\title{
Unified Communications
}

DOI 10.1007/s12599-009-0062-3

\author{
The Authors \\ Dr. Kai Riemer \\ The University of Sydney \\ Discipline of Business \\ Information Systems, Faculty \\ of Economics \& Business \\ Building $\mathrm{H} 69$ \\ NSW 2006 \\ Australia \\ k.riemer@econ.usyd.edu.au \\ Dipl.-Ing. Stefan Taing \\ Ludwig-Maximilians- \\ Universität München \\ Institut für Information, \\ Organisation und Management \\ Ludwigstr. 28/VG/II \\ 80539 München \\ Germany \\ stefan.taing@lmu.de
}

Received: 2009-04-15

Accepted: 2009-05-15

Accepted after two revisions

by Prof. Dr. Sinz.

This article is also available in German in print and via http://www.wirt schaftsinformatik.de: Riemer K, Taing $S$ (2009) Unified Communications. WIRTSCHAFTSINFORMATIK. doi: 10.1007/11576-009-0184-8.

\section{Subject matter}

Unified Communications (UC) stands for integrated, managed communication (Picot et al. 2008). UC systems are the result of the convergence of telecommunications and information technology; they integrate traditional and novel communication media (speech, text, video) and devices (phone, computer) with presence information and further collaboration features (Riemer u. Frößler 2007). A key aspect is the integration of UC functionality with business information systems (e. g. ERP, CRM software) and therefore with the core business processes of a corporation.
The aim of this catchword article is to introduce the UC concept and corresponding systems to illustrate its relevance for corporate practice using typical application scenarios, and to provide an outlook from the point-of-view of business and information systems (BISE) research.

\section{Drivers of UC development}

From an organizational perspective, the development of UC is being driven by typical problems of distributed collaboration in modern work contexts. The number of possible communication options has increased over the past few years so that today the average user is confronted with a heterogeneous range of available media and devices. Typically, this leads to a high complexity for the recipient, as s/he has to manage a myriad of communication devices and media, as well as for the initiator who needs to try out different communication options in order to finally reach the recipient (Lazar 2006). Often, the results are failed communication attempts, lost time, and frictions in team collaboration. Apart from a generally poor availability for communication, people often also experience work interruptions, which are especially disruptive to concentration when being immersed in complex, knowledge-intensive tasks; people who are confronted with the demands of increased communication complexity experience what is termed ,interaction overload“ (de Poot et al. 2005). Vendors of UC solutions promise to improve the user's individual communication management through media integration and rule-based coordination of his/her media mix as well as to improve the availability for communication in teams and business processes by creating awareness using presence signaling functionality (Jennings 2006).

From a technology perspective, the development of UC is driven by advances in IP-based infrastructures as well as by innovations in software-based communication media such as instant messaging. In that respect, cost reductions play a major role, as IP-based systems can replace outdated legacy telephone infrastructures.
Moreover, UC systems can contribute significantly to complexity reduction: A separate, dedicated infrastructure network for speech communication becomes redundant when migrating to a unified IP network. According to these developments and the above-mentioned convergence, UC systems are being developed and marketed by providers from the telecommunications (e. g. Siemens), information technology (e. g. IBM), and business software (e. g. Microsoft) sectors.

\section{Key modules of unified communications systems}

The feature range of UC systems can be divided into six key modules which in combination represent the full UC vision as propagated by its vendors (see Fig. 1 for a summarizing overview):

1. IP Infrastructure module: This module provides for the physical data transport of communication streams as IPbased transmission is realized through components such as servers, routers, switches, and the corresponding end user devices. Hardware and software components make up the core of this module. When it comes to end user interfaces, so-called softphones are also part of the infrastructure module since they replace hardware-based phones with a software application on the user's computer.

2. Communication media module: An essential component of UC systems is the range of provided synchronous communication media such as telephony, video communication, or instant messaging. For all media, the systems enable both two person communication as well as multi-person conferencing. UC vendors often also provide asynchronous communication media such as e-mail or blogs, but these are not in the focus of the UC idea.

3. Media/channel integration module: The integration of the above-mentioned communication media is realized through an integrated message handling component and a rule-based coordination layer. A message portal, 


\section{1}

\section{We proudly present}

BUSINESS \& INFORMATION SYSTEMS ENGINEERING
Springerlink

www bise-journal.org

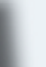




\begin{tabular}{|c|c|c|c|c|c|c|}
\hline $\begin{array}{l}\text { Key } \\
\text { modules }\end{array}$ & IP-infrastructure & $\begin{array}{c}\text { Communication } \\
\text { media }\end{array}$ & $\begin{array}{l}\text { Media/channel } \\
\text { integration }\end{array}$ & $\begin{array}{l}\text { Presence } \\
\text { signaling }\end{array}$ & Collaboration & Contextualization \\
\hline Details & $\begin{array}{l}\text { IP-based } \\
\text { telephony (VoIP) } \\
\text { Extension of } \\
\text { traditional } \\
\text { telephony } \\
\text { VoIP over } \\
\text { wireless LAN }\end{array}$ & $\begin{array}{l}\text { - Unified messaging } \\
\text { Asynchronous } \\
\text { and synchronous } \\
\text { media }\end{array}$ & $\begin{array}{l}\text { Rule-based call } \\
\text { diversion } \\
\text { Follow-me } \\
\text { feature } \\
\text { - Preference group } \\
\text { concept }\end{array}$ & $\begin{array}{l}\text { Presence status } \\
\text { Automatic } \\
\text { generation of } \\
\text { signals on the } \\
\text { device/media } \\
\text { level } \\
\text { Individual } \\
\text { signalling }\end{array}$ & $\begin{array}{l}\text { Conferences } \\
\text { Ad-hoc } \\
\text { application } \\
\text { sharing } \\
\text { - Group calendar } \\
\text { - Shared file } \\
\text { storage }\end{array}$ & 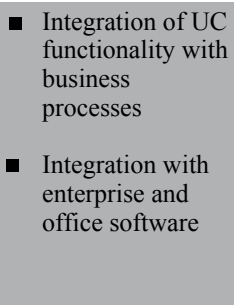 \\
\hline Examples & $\begin{array}{l}\text { - VoIP phones } \\
\text { - Softphones }\end{array}$ & $\begin{array}{l}\text { Softphone with } \\
\text { Video, email, IM } \\
\text { and voicemail } \\
\text { integration }\end{array}$ & $\begin{array}{l}\text { Single number } \\
\text { reachability } \\
\text { Softphone with } \\
\text { rule editor }\end{array}$ & $\begin{array}{l}\text { Cisco Presence } \\
\text { - AOL Messenger } \\
\text { - Skype }\end{array}$ & $\begin{array}{ll}\text { - } & \text { Meetingplace } \\
\text { - Webex } \\
\text { - Lotus Sametime }\end{array}$ & $\begin{array}{l}\text { - SAP integration } \\
\text { - Office integration }\end{array}$ \\
\hline Focus & $\begin{array}{l}\text { Hardware and } \\
\text { infrastructure }\end{array}$ & $\begin{array}{l}\text { Media and } \\
\text { devices }\end{array}$ & $\begin{array}{l}\text { Individual and gro } \\
\text { communication } \mathrm{m}\end{array}$ & $\begin{array}{l}\text {-oriented } \\
\text { agement }\end{array}$ & - Teamwork & $\begin{array}{l}\text { Organizational } \\
\text { integration }\end{array}$ \\
\hline
\end{tabular}

Fig. 1 Unified Communications key modules

well known from unified messaging solutions, allows to access voice mail messages as audio files, e. g. delivered via email, and the conversion of text to speech (Clark 1999; Rosenberg 2005). Through configurations in the rule-based coordination layer, incoming calls can be diverted automatically to preferred and currently available devices (Jennings 2006). For doing so, the different types of media (text, audio, video), devices (mobile phones, IP phones, etc.), and software clients (instant messenger, softphone, video clients) need to be configured and registered with the UC system. Call diversion rules can be quite complex; they can refer to a particular caller ID, be based on a time of day, or depend on different end user devices. Moreover, a unified phone number, which is independent of any device, simplifies the user's channel management (Rosenberg 2005).

4. Presence signaling module: Different ways of signaling a person's availability for communication, such as predefined ("available“, "busy"), individual ("with client $X^{\prime \prime}$ ), or technical ("on-the-phone") states, provide an improvement of the availability of team members and at the same time a decrease in the number of unwanted interruptions (de Poot et al. 2005). In contrast to simple instant messaging, $\mathrm{UC}$ is capable of enabling much more complex forms of presence signaling. On the one hand, the user's presence status can be deduced from technical devices; on the other hand, user presence states can be aggregated in order to signal the status of a group or be attached to any object within thirdparty software applications (e. g. files) (Riemer 2007). For example, a group status enables users to stay informed about the availability of an entire group, e. g. when someone wants to initiate a team conference.

5. Collaboration module: This module is more or less concerned with media richness. The idea is to enhance communication by enabling users to upgrade a simple voice conversation with collaboration services, thereby giving them the opportunity to engage in ad-hoc application sharing, e.g. for co-editing a document, or to change a bilateral voice call to a multi-person video conference.

6. Contextualization module: This module refers to the embedding of UC functionality with business systems and processes (Mohamed 2007). By doing so, UC enables users to initiate ad-hoc communication and collaboration from within their immediate work context. A typical feature is the so-called "click-to-call“ button, e. g. as provided in the corporate Intranet, which enables to initiate a direct call without having to know and type in a person's phone number.

\section{Application scenarios}

Apart from the above-mentioned advantages in the management of corporate communication infrastructures, e. g. complexity reduction and cost savings from abolishing legacy infrastructures, UC solutions especially promise to bring about changes and improvements to distributed communication and coordination practices. The following scenarios exemplarily illustrate the potential of UC which derives from the combination of media integration, rule-based coordination, and contextualization.

\subsection{Document-oriented communication in time-critical processes}

A core idea of UC is enabling ad-hoc communication from within people's immediate work context. Using technical interfaces, it is possible to attach availability states to any object within third-party software. By doing so, people are able to get in contact with the authors of electronic documents when using the software without having to find out about their identity, contact details, or current availability. This is especially important in time-critical processes. In a hospital scenario, for example, the availability status of medical specialists can be attached to any electronic patient records or lab reports that they have edited. In case of an emergency the attending doctor is immediately and easily able to initiate a communication with the respective 
experts who can then provide further details or background information on the patient's condition or medical history.

\subsection{Competence-based call diversion in mobile work contexts}

Another scenario for applying UC is in role-based or competence-based communication. Through linking of UC systems with competence databases, users can be enabled to get in contact with experts immediately when searching for specific competencies. In this case, the availability status is not attached to documents but to specific organizational roles. This is especially useful in a field service (or traveling salesman) scenario, when a piece of information or expert opinion is required just when the employee is at a remote site. Examples are the insurance broker who wants to make a deal with the customer, the field technician who needs technical assistance, or the journalist at the location of an event. In all cases, the direct accessibility of experts from the head office is important. An expert search combined with a role-based call diversion feature enables the employee to establish ad-hoc contact with a suitable and available expert using a mobile device (laptop computer, smartphone) without having to know their name, contact details, work context, or current availability.

\subsection{Case-based conference initiation in interdependent processes}

Apart from the above-discussed simplification of establishing contact in distributed work contexts, the context embedding of UC systems further allows for a (semi-) automatic initiation of interpersonal communication based on certain process states. For example, a newly developed enterprise resource planning system in a fashion company may provide, for every step of a procurement process, a contextualized contact list (with availability states) of all relevant decision makers; thus it becomes possible to initiate an ad-hoc phone or video conference call for dealing with arising problems. In a production context, a deeper process integration of UC might enable a PPS system to autonomously initiate a phone conference between the available decision makers in order to deal with a breakdown of the production line or unexpected material shortages.

\begin{tabular}{|c|c|c|}
\hline Level & UC potentials & UC challenges \\
\hline Organization & $\begin{array}{l}\text { - Allows for new organizational forms } \\
\text { - More effective virtualization and } \\
\text { distribution of project work } \\
\text { - More effective communication in } \\
\text { novel and mobile work contexts }\end{array}$ & $\begin{array}{l}\text { - Cautious introduction, change } \\
\text { management, internal communications, } \\
\text { expectation management necessary } \\
\text { - Organizational rules and norms } \\
\text { for UC usage needed } \\
\text { - Embedding of UC in existing } \\
\text { communication culture important }\end{array}$ \\
\hline Group, process & $\begin{array}{l}\text { - Enables new work practices } \\
\text { - Differentiated team } \\
\text { communications } \\
\text { - Communication-enabled } \\
\text { business processes }\end{array}$ & $\begin{array}{l}\text { - Openness (Nutzungsoffenheit) of UC } \\
\text { systems requires time and freedom } \\
\text { to experiment with the systems } \\
\text { - Support adoption processes and } \\
\text { configuration of appropriate } \\
\text { media mixes/configurations }\end{array}$ \\
\hline Individual & $\begin{array}{l}\text { - Active, individual management of } \\
\text { availability for communication } \\
\text { - Management of media and } \\
\text { channel complexity }\end{array}$ & $\begin{array}{l}\text { - Questions of UC usability } \\
\text { (Information overload) } \\
\text { - Deal with people's fear of surveillance } \\
\text { through presence information }\end{array}$ \\
\hline Infrastructure & $\begin{array}{l}\text { - Cost advantages when switching } \\
\text { to IP-based infrastructures } \\
\text { - Complexity reduction when } \\
\text { unifying corporate networks } \\
\text { on the basis of IP }\end{array}$ & $\begin{array}{l}\text { - Migration from PSTN to IP } \\
\text { - Technical integration of legacy } \\
\text { systems and devices } \\
\text { - Interlinking of UC systems and } \\
\text { devices from different vendors } \\
\text { - IP-focused risk management }\end{array}$ \\
\hline
\end{tabular}

\subsection{Active availability management in knowledge-intensive teamwork}

Knowledge-intensive tasks require people to on the one hand have direct access to information sources and knowledge bearers, while on the other hand people need time for intense concentration and uninterrupted work. In such a context (as is typical in a consultancy firm), UC systems are supposed to improve the availability of knowledge bearers (experts) as well as to allow knowledge workers to have times for concentrated work by way of an active availability management (cf. Riemer 2007). Traditional behavior would be to turn off all devices or to signal "not available". However, if a consultant needs to be available for some of his/her direct team mates, it is necessary to distinguish between wanted and unwanted communication attempts. Here, a rule-based coordination of availability and a customizing of the presence signaling feature (Riemer u. Klein 2009) might enable the consultant to differentiate his/her status in such a way that for all users outside the immediate team the signal shows "not available" while the consultant is still available for team members.

\section{Significance for the BISE domain}

Unified communications as a topic is not entirely new. However, while most UC systems on the market have outgrown their prototype stage, existing installations in practice currently only exhibit parts of the full UC vision and often concentrate on one or two of the above mentioned modules. On the other hand, many large and well-known companies (e. g. Cisco, IBM, Microsoft, Siemens) have entered the market as UC providers and are working hard towards establishing this system class through development and marketing. Consequently, the topic has significant relevance for both practice as well as BISE research. As a starting point, it is necessary to better understand the specific characteristics of UC systems.

An essential characteristic of UC systems is what can best be expressed in the German language as Nutzungsoffenheit, a type of openness whereby the artifact does not lend itself to or even determine a particular form of usage and whereby its potential and likely effects in practice cannot be deduced from an analysis of its features (Riemer et al. 2007). In fact, the actual use and benefit of UC systems only unfold through the adoption by their users, when systems become part of group or organizational practices. Against this background, further research carried out in practice (e. g. as case studies) is needed in order to get to better understand this type of system. Existing research has shown that complex UC systems should be treated as platform technologies which need customizing to fit a certain organizational context (Riemer u. Klein 2009). For UC vendors these observations exhibit certain challenges in terms of marketing these systems, since the potential of UC 
cannot be illustrated by simply presenting system features. Moreover, it is hardly possible to carry out a cost-benefit analysis before implementation, since applying a UC system immediately leads to costs while benefits only manifest themselves slowly through learning and appropriation by its users. Investments in UC technologies hence need to be treated as creating potentials rather than bringing about immediate effects.

The possible potential and challenges of UC in context can be illustrated best by using a multi-layer model. The items listed in Tab. 1 can at the same time be interpreted as a BISE research agenda. Provided that full installations of UC systems become available in practice, future studies should explore the true potential of UC systems and investigate how challenges can be managed. In doing so, a range of open research questions will arise. A more comprehensive research agenda can be found in Riemer and Frößler ([8]).

\section{Conclusion and outlook}

The current UC market situation is characterized by a distinct technology push on the part of the UC vendors. Most notably, providers from the collaboration software domain, such as IBM or Microsoft, and those from the IP infrastructure sector (e. g. Cisco) are pushing their products onto the market. The relative novelty of the systems as well as a range of unanswered technical and organizational questions impede the spread of UC systems. Therefore, the opportunity exists for BISE researchers to assist corporations in implementing UC systems using design-oriented research studies. Through providing concrete examples and objective accounts of quantitative and qualitative benefits, action research and case studies can help to put this rather technology-focused topic on the agenda of top managers. Moreover, studies on the group-level of analysis are needed in order to better understand processes of adoption and potential benefits of UC for distributed team collaboration.

Apart from an ongoing improvement of the stability and maturity of UC systems, current developments on the technology level point in two directions: On the one hand, vendors are working towards a better inter-vendor and inter-organizational linking of UC systems, e. g. via presence federation (i. e. the propagation and con- necting of status information); on the other hand, developments point towards more complex process integration scenarios (in terms of so-called communicationenabled business processes).

\section{References}

Clark C (1999) Unified messaging: where's the market. Wireless Review 16(3):100-103

de Poot H, Mulder I, Kijl B (2005) How do knowledge workers cope with their everyday job? eJOV - The Electronic Journal for Virtual Organizations and Networks 9:70-88

Jennings C (2006) Why unified communications need presence federation. Business Communications Review (12):18-22

Lazar I (2006) Integrating telephony, IM, video and mobility with presence. Business Communications Review (6):28-31

Mohamed A (2007) Work together any place, any time. Computer Weekly (2007-03-06):38-40

Picot A, Riemer K, Taing S (2008) Unified Communications. In: Kurbel K et al (eds) (2008) Enzyklopädie der Wirtschaftsinformatik, $2^{\text {nd }}$ edn. Oldenbourg, München. http://www. enzyklopaedie-der-wirtschaftsinformatik.de/ wi-enzyklopaedie/lexikon/informations systeme/kommunikations-und-kollaborations systeme/Unified-Communication/index.html. Accessed 2009-05-07

Riemer K (2007) Präsenzbasierte Echtzeitkommunikation - Eine prototypbasierte Untersuchung der Nutzbarkeit im Unternehmensberatungskontext. In: Oberweis A et al (eds) eOrganisation: Services, Prozess-, Market-Engineering, vol 1. Universitätsverlag Karlsruhe, pp 751-768

Riemer K, Frößler F (2007) Introducing real-time collaboration systems: development of a conceptual scheme and research directions. Communications of the Association for Information Systems 20:204-225

Riemer K, Frößler F, Klein S (2007) Real time communication - modes of use in distributed teams. $15^{\text {th }}$ European conference on information systems. St. Gallen

Riemer K, Klein S (2009) Presence signalling in unified communication systems - a framework for adaptation in context. In: Hansen HR et al (eds) Business Services: Konzepte, Technologien, Anwendungen, Österreichische Computer Gesellschaft, Wien, pp 265-274

Rosenberg AM (2005) Do you need to replace enterprise voice mail? Business Communications Review (10):36-41
WWW.GABLER.DE

„Brockhaus der

deutschen Familien-

unternehmen"

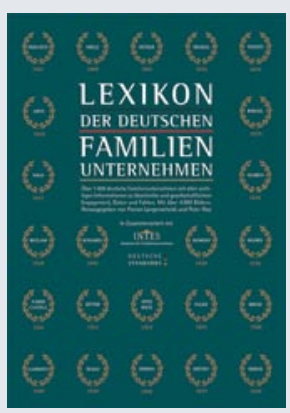

Florian Langenscheidt (Hrsg.)

Lexikon der deutschen Familienunternehmen Rund 1.000 deutsche

Familienunternehmen mit allen wichtigen Informationen zu Geschichte und gesellschaftlichem Engagement, Daten und Fakten. Mit 4.000 Abbildungen.

2009. 1000 S. Geb.

EUR 78,00

ISBN 978-3-8349-1640-2

Das „Lexikon der deutschen Familienunternehmen" ist die erste, nach enzyklopädischen Prinzipien herausgegebene Gesamtdarstellung der wichtigsten Familienunternehmen aus den Bereichen Konsumund Investitionsgüter sowie Dienstleistungen und Produktion auf dem deutschen Markt.

Einfach bestellen: kerstin.kuchta@ gwv-fachverlage.de Telefon +49(0)611. 7878-626

KOMPETENZ IN SACHEN WIRTSCHAFT

Änderungen vorbehalten
Erhältlich im Buchhandel oder beim Verlag.

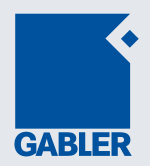

